\title{
REVIEW
}

\section{Phenotypic plasticity and epigenetics of fish: embryo temperature affects later-developing life-history traits}

\author{
Bror Jonsson*, Nina Jonsson \\ Norwegian Institute for Nature Research, Gaustadalléen 21, 0349 Oslo, Norway
}

\begin{abstract}
Temperature during embryonic development affects ecological traits and influences the ability to rapidly adapt to the prevailing conditions in changing environments. Here, we review examples of how these developmental effects are manifested in life-history traits from studies of various fish species, with examples of impacts on somatic growth, age at migration and maturation, allocation of resources to gonads and egg size. Temperature during embryogenesis appears important for some behavioural decisions, such as when maturing Atlantic salmon Salmo salar return home from the ocean for spawning in distant rivers during summer. In some species, early temperature influences sex determination. The temperature level during embryogenesis may preadapt the fish to maximize offspring production under the thermal conditions encountered at the embryo stage. This thermal influence is a phenotypically plastic response that triggers polyphenism in salmonids and may be a first step in speciation of North American darters (Percidae). The responses to early temperature appear to be regulated by epigenetic mechanisms, such as DNA methylation, histone modification and micro RNAs.
\end{abstract}

KEY WORDS: Phenotypic plasticity - Epigenesis - Gene expression · Life-history characters · Polyphenism

\section{INTRODUCTION}

Early temperature influences phenotypic plasticity, i.e. the ability of individual genotypes to produce altered phenotypes when exposed to different conditions (Pigliucci et al. 2006). This includes the ability of organisms to change developmental trajectories, activities and resource allocation in response to variation in environmental conditions. Research suggests that early temperature plays a critical role in brain development and flexibility influencing cognition, behaviour, social skills, stress responsiveness and personality development of mammals such as humans and mice (Malekpour 2007, Gudsnuk \& Champagne 2011). Furthermore, ecological traits expressed by juveniles and adults can be affected by the temperature during embryo development through epigenetic modifications, where genes can be activated or silenced by molecular mechanisms

${ }^{*}$ Corresponding author: bror.jonsson@nina.no that can heritably alter gene expression without changing the DNA sequence (Best et al. 2018, Horsthemke 2018). Although poorly investigated, it is reasonable that similar relationships hold for many other vertebrates.

Genotypes govern, and environment modifies, phenotypes. According to Lindström (1999), the earlier the environmental effect, the stronger its long-term impact can be. Environmental temperatures affect aquatic poikilotherms during embryogenesis within the eggshell and can have long-term phenotypic effects recognizable in the ecology of the species. Tåning (1952) observed that temperature during embryonic development affects the number of vertebrae in brown trout Salmo trutta. More recently, it was revealed that embryonic temperature affects muscle fibre recruitment in different fishes, including zebrafish Danio rerio (Johnston et al. 2009), Senegal sole Solea senegalensis (Campos et al. 2013)

(C) The authors 2019. Open Access under Creative Commons by Attribution Licence. Use, distribution and reproduction are unrestricted. Authors and original publication must be credited. 
and Atlantic cod Gadus morhua (Bizuayehu et al. 2015). However, less is known about how early temperature can modify ecological characters such as growth rate of juveniles, adult body size and other fitness-related traits. This was the background for the present review on phenotypic plasticity and epigenetic effects in fishes.

Here, we focus on how temperature during early ontogeny affects ecological traits. We show how early temperature affects the physiology of species and how these changes can be influenced by epigenetic modifications, i.e. changes in genetic expression, without changing the genetic structure of populations (Turner 2009). At the end, we discuss the wider significance of phenotypic variation caused by variation in temperature during embryogenesis and suggest further research tasks. We are aware that early temperature level is one of several environmental variables that can have lasting impacts on phenotypic expression. Other stressors that affect embryos include hypoxia and chemical contamination (cf. Ho \& Berggren 2012, Dubinska-Magiera et al. 2016, Wang et al. 2016, Liu et al. 2017). Temperature also has pervasive, controlling effects on the ecology and physiology of poikilotherms later in life (e.g. Jonsson et al. 2013), but it is beyond the scope of this paper to discuss thermal influences occurring at later life stages and environmental stressors other than embryo temperature.

\section{ECOLOGICAL EFFECTS OF TEMPERATURE AT THE EMBRYONIC STAGE}

Several ecological traits appearing at a later life stage may be influenced by the temperature affecting the embryo within the egg shell, including developmental rate, growth and reproductive allocation (Fig. 1).

\subsection{Growth, size and developmental rate}

Thermal effects of embryo temperature on growth were experimentally tested on Atlantic salmon Salmo salar by Finstad \& Jonsson (2012). Eggs and alevins were incubated until the onset of external feeding at either heated or natural (= cold) temperatures of the River Imsa, Norway, or transferred from ambient to heated water at the time of hatching (= mixed temperature). This created 3 different embryonic temperature treatments. The cold group received natural river water (mean $\pm \mathrm{SD}: 2.6 \pm 0.4^{\circ} \mathrm{C}$ ) and the warm

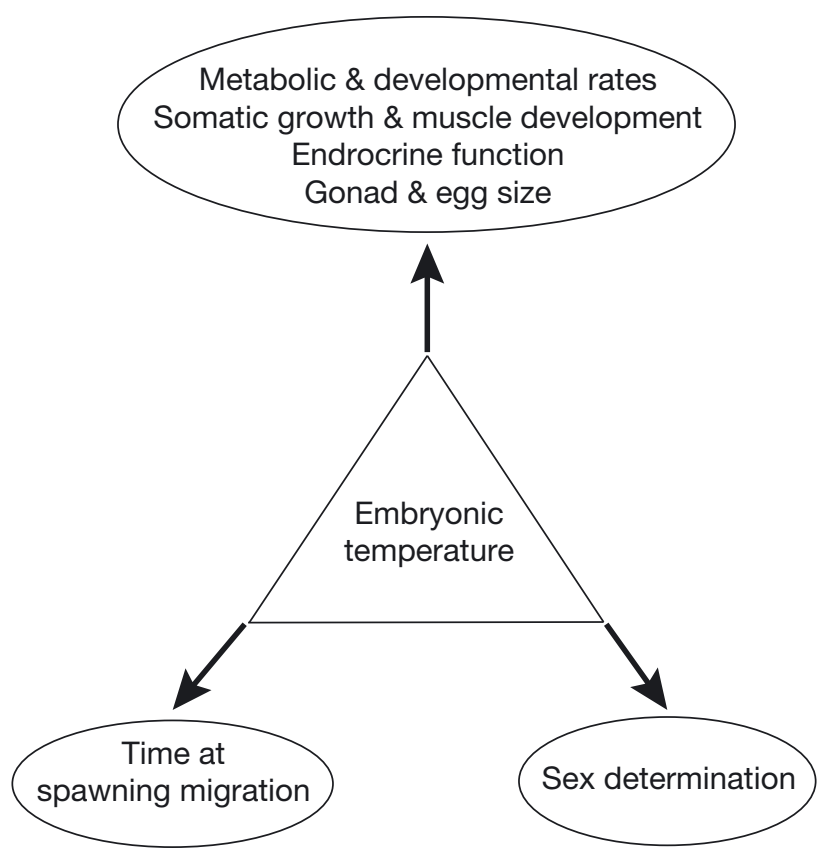

Fig. 1. Temperature during embryo development can influence later expressed fitness-related ecological, behavioural and physiological traits of fishes

group received water at on average $4.6^{\circ} \mathrm{C}$ above ambient temperature, which is an expected winter temperature in the river towards the end of this century. Thus, the warm treatment lasted from fertilization until exogenous feeding started. The mixed group received natural cold river water until hatching, whereupon the larvae received heated water until the commencement of exogenous feeding. From the start of exogenous feeding onwards, all 3 groups were reared under identical, natural thermal conditions. Somatic growth of the groups was tested at 8 different temperatures between $6^{\circ}$ and $24^{\circ} \mathrm{C}$. Maximum growth of juvenile $S$. salar was higher in the heated water than at the other 2 incubation temperatures. Growth was similar at cold and mixed temperatures. There was no significant difference in the thermal scaling of growth among groups or in upper $\left(25^{\circ} \mathrm{C}\right)$ or lower $\left(6^{\circ} \mathrm{C}\right)$ thermal limits for growth. Also, the optimal temperature for growth $\left(19^{\circ} \mathrm{C}\right)$ was similar between treatments. The experiment revealed, however, that juvenile $S$. salar incubated in heated water grew better than the others at the optimal temperature (Finstad \& Jonsson 2012). Mortality prior to the growth experiment was low and similar in all groups, thus excluding selection as an explanation of the results. This finding was later supported by Burgerhout et al. (2017), who reported that embryos of $S$. salar incubated at $8^{\circ} \mathrm{C}$ grew better than those from eggs incubated at $4^{\circ} \mathrm{C}$. Thus, temperature during 
embryo development affects growth of the juveniles in fresh water, an important finding, because size at age is perhaps the most important ecological trait influencing fitness of fishes. It influences competitive ability, social status, reproductive success and ability to evade predators (McLennan et al. 2016). To what extent plasticity in this trait varies among populations of the species is unknown.

The observation that temperature during embryogenesis influences growth of juveniles may explain the earlier field observation that specific growth rate of $S$. salar during the first year of life in the River Imsa correlated positively with water temperature during winter, when the embryos developed within the eggshell in the bottom substratum of the river. Among years, growth did not vary with ambient temperature in the subsequent summer season in the investigated system (Jonsson et al. 2005). Typically, $S$. salar of the River Imsa smolt and migrate to sea at 2 yr of age, although large 1 yr old individuals will also smolt and migrate (Jonsson et al. 2016). The proportions of $1 \mathrm{yr}$ old smolts varied among years and increased with water temperature during embryogenesis but not with temperature in the subsequent summer (Jonsson et al. 2005). This exhibits another significant effect of temperature during the embryonic stage for the developmental rate of $S$. salar. Fast growth, stimulated by high temperature at the embryo stage, can shorten river life by 1 yr. Those that smolt at the regular age become larger than the early smolting fish, and with that, size after each year at sea later in life. In addition, younger smolts tend to stay and feed longer at sea before attaining maturity (O'Connell \& Ash 1993, Jonsson et al. 2003, Tattam et al. 2015). In this way, high embryo temperature affects future growth and size of $S$. salar.

Similarly, in Solea senegalensis, egg incubation temperatures modify growth performance of juveniles. In 2 experiments, Carballo et al. (2018) showed that offspring incubated at $20^{\circ} \mathrm{C}$ grew better than those incubated at $16^{\circ} \mathrm{C}$, with additional effects on the endocrinology of the fish, as explained in Section 5 on physiological effects of early temperature.

In addition, temperature experienced by parents prior to egg fertilization can affect offspring performance by shaping their reaction norm for growth as a maternal effect (Mousseau \& Fox 1998). Salinas \& Munch (2012) reported that sheepshead minnow Cyprinodon variegatus reared in $24^{\circ}, 29^{\circ}$ or $34^{\circ} \mathrm{C}$ for $30 \mathrm{~d}$ during egg maturation produced offspring that grew best at the temperatures that were experienced by their mothers during egg maturation, prior to spawning. The offspring increased as much as 30\% in growth over 1 generation, which exceeds a singlegeneration rate of adaptive evolution by an order of magnitude. Thus, the mothers adaptively programmed their offspring to grow at a maximum rate at the temperature they experienced during the egg maturation. Similarly, Shama \& Wegner (2014) tested for adaptive transgenerational plasticity in threespined stickleback Gasterosteus aculeatus. They found that developmental acclimation of mothers at elevated temperature had negative effects on offspring body size. The offspring were smaller when mothers were reared at $21^{\circ} \mathrm{C}$ than at $17^{\circ} \mathrm{C}$. However, the higher temperature caused the daughters to produce larger offspring. A smaller body size in warmer water may be advantageous in terms of lower oxygen demands (Forster et al. 2012), but the mechanism underlying the transfer of environmental information is unknown and appears to differ over the 2 generations. This maybe favourable, however, as the effect on offspring size depends on whether temperature changes are acute or long term and lasts over generations (Shama \& Wegner 2014).

\subsection{Reproductive traits}

Through its effect on growth, temperature during embryogenesis affects energy allocation to eggs and sperm. After smolting, the groups of $S$. salar used by Finstad \& Jonsson (2012) were reared to adulthood under identical, natural thermal conditions in seawater. Those that developed from warm-incubated eggs grew the largest, had the highest mass-length relationship and developed larger eggs and higher gonad mass when adjusting for adult length and condition factor (Jonsson et al. 2014). Production of larger, more energy-rich eggs, is one way in which early temperature influences growth and size of offspring. There was no similar effect of thermal environment during larval development, indicating that the warming effect occurred prior to egg hatching. Furthermore, the thermal treatment did not affect age of maturity or fecundity of the experimental groups. Thus, temperature during embryogenesis affected the expression of some adult life-history traits, a mechanism by which $S$. salar may rapidly change the size of their eggs to the thermal environment they experienced as embryos. Furthermore, mass of eggs produced by next-generation females was also larger when their mothers experienced warmer water during the last 2 mo of egg maturation, relative to those with mothers that experienced unheated river water (Jonsson \& Jonsson 2016). 
There was no paternal effect on offspring egg mass. Thus, other conditions being equal, thermal conditions experienced during egg maturation can influence the size of eggs produced by offspring and thus hand down an effect from the previous generation on the amount of yolk available to the offspring. Large eggs have higher survival at reduced oxygen concentration than smaller eggs (Einum et al. 2002, Braun et al. 2013). Furthermore, high water temperature reduces the efficiency of yolk conversion to body tissue (Fleming \& Gross 1990), also making a mechanism that increases egg size advantageous in warmer environments. How this maternal effect is transferred over generations is not yet known.

\section{EARLY TEMPERATURE EFFECTS ON BEHAVIOUR}

It is known that temperature influences the behaviour of poikilothermic vertebrates (Shine \& Olsson 2003, Colchen et al. 2017), but interestingly, temperatures during embryogenesis can also influence later behavioural decisions, although this effect is less studied. In domesticated chicks Gallus gallus domesticus, Bertin et al. (2018) reported that chronic exposure of eggs to low incubation temperature caused higher neophobic responses compared to control birds when exposed to novel food and novel environment tests.

In Salmo salar, Jonsson \& Jonsson (2018) recently reported effects of higher temperature during egg incubation on the time of their return from the ocean for spawning. Jonsson \& Jonsson (2018) released groups of $S$. salar smolts developed from eggs incubated in natural River Imsa water at approximately $4^{\circ}$ and $7^{\circ} \mathrm{C}$, considered 'cold' and 'warm' temperatures. After smolting, ca. $15 \mathrm{~cm}$ long, the post-smolts migrated to sea and returned to the River Imsa for spawning 1 yr later (Jonsson et al. 2016). Their feeding area is in the North Norwegian Sea between the Faroese Islands and Iceland, $1000 \mathrm{~km}$ away from their home river. The decision about when to begin migrating home is made about half a year prior to spawning time in the autumn (Hansen et al. 1993, Quinn et al. 2016). At the start of the return migration, fish do not know whether the temperature in the subsequent winter in the home river will be warmer or colder than what they are genetically adapted to. However, climate changes are typically directional and often rapid (Peters et al. 2012). Thus, a phenotypically plastic time of return directed by the winter temperature at the embryo stage may be an effective way to adjust the timing of the return migration, to maximize oceanic feeding and return at a proper time for spawning. The experiment showed that maturing $S$. salar that had developed from warm embryos returned from the North Atlantic Ocean to the Norwegian coast on average 2 wk later than those that developed from cold embryos (Jonsson \& Jonsson 2018). The later return was independent of body size of the smolts at outmigration and held for offspring of 3 different populations tested. Thus, this reaction to early incubation temperature appeared general for the species.

Hence, thermal climate during early development may pre-adapt the fish to the temperature they expect to encounter during the embryogenesis. They may feed longer in the ocean before starting the homing migration, if the experienced temperature is higher than expected from their genetic program. The mechanism driving this phenotypic plastic response to early temperature has not been investigated.

\section{TEMPERATURE EFFECTS ON SEX DETERMINATION}

The sex of fishes is determined by genetic, epigenetic and environmental factors and their interactions (Pittman et al. 2013). Heterogametic sex chromosomes are known in only $6-10 \%$ of investigated fish species (Kitano \& Peichel 2012, Navara 2018). In most cases, there is a more primitive polygenetic sex determination. According to Ospina-Álvarez \& Piferrer (2008), temperature-influenced sex differentiation occurs in 33 cichlids and several other species. Furthermore, larvae of genetically female flatfishes of the genus Paralichthys can change sex when exposed to warm water (Montalvo et al. 2012a,b), and Nile tilapia Oreochromis niloticus exhibit sex reversal in some lakes (Nivelle et al. 2019).

Mangrove killifish Kryptolebias marmoratus have a mixed breeding strategy, whereby individuals can either be self-fertilizing hermaphrodites or crossbreeding (Taylor 2012). Ellison et al. (2015) reported that environmental temperature modulates sexual identity of the species. In 2 strains tested, there were no males at $25^{\circ} \mathrm{C}$, and the population had to be hermaphroditic. At $18^{\circ} \mathrm{C}$, on the other hand, there were $50 \%$ males or more and consequently crossbreeding. The proportion of males differed between the 2 strains, indicating that there were also genetic differences among populations for the trait.

Sex is determined during a sensitive period of early development (Valenzuela et al. 2003). Often, more 
males are produced as the temperature increases (Ospina-Álvarez \& Piferrer 2008, Hayashi et al. 2010, Shao et al. 2014), but in some species, such as channel catfish Ictalurus punctatus (Patiño et al. 1996), Korean rockfish Sebastes schlegelii (Omoto et al. 2010), European seabass Dicentrarchus labrax (Baroiller \& D'Cotta 2001) and dwarf perch Micrometus minimus (Schultz 2008), more females are produced in warmer than colder water. In M. minimus, Schultz (2008) reported that low temperatures early in the season resulted in relatively more males than in warmer water later in the season. Olive flounder $P$. olivaceus is different in that both high and low temperatures induce monosex male populations; at intermediate temperatures, the sex ratio approaches evenness in this species (Baroiller \& D'Cotta 2001). Hence, there are several exceptions to the rule that higher temperatures are correlated with more male offspring. Little is known about the evolutionary advantage(s) of temperature-dependent sex determination, although it appears reasonable to assume that it is because of reduced survival of the sex that increases in abundance when egg incubation temperature changes.

\section{PHYSIOLOGICAL EFFECTS OF EARLY TEMPERATURE}

Temperature during embryogenesis influences the physiology of fish. Schnurr et al. (2014) reported that temperature during early development affected the energy metabolism pathways and acclimation capacity in later life of Danio rerio. Moreover, experiments by Vernerback (2016) indicated that warmer water during egg incubation reduced metabolic rates as inferred by reduced ventilation rates in juvenile Salmo salar. Furthermore, Cook et al. (2018) investigated whether temperatures experienced by brook trout Salvelinus fontinalis embryos affected mass and routine metabolic rates of free-swimming fry. They reported that mass differences among fry were influenced by the population of origin as well as by initial rearing and final acclimation temperatures. Variation in mass-adjusted resting metabolic rate (RMR) of fry was also strongly accounted for by source population, acclimation temperature and individual mass. A significant interaction between population RMR and final acclimation temperature indicated that not all $S$. fontinalis populations responded in the same way to temperature changes.

Muscle development is influenced by temperature during the embryo stage. Stickland et al. (1988) reported that post-hatching embryos of $S$. salar, incubated at higher temperatures, develop larger, but fewer muscle fibres than those incubated at lower temperatures. This result parallels the findings of Campos et al. (2013) from studies of Solea senegalensis. Temperature had both short- and long-term effects on growth and muscle cellularity. Furthermore, embryo temperature has persistent effects on thermal acclimation capacity, as exhibited for $D$. rerio (Scott \& Johnston 2012). These authors observed differences in expression of individual genes involved in energy metabolism, cell stress and muscle contraction that influenced the reaction norm for growth. Such thermal plasticity of muscle growth must arise through changes in a multitude of physiological and endocrinological pathways, in which epigenetic gene regulation is likely to play an essential role as demonstrated for S. senegalensis (Carballo et al. 2018). These authors reported that higher egg incubation temperatures enhance the mRNA abundance of thyroid-related genes and of a retinoic acid degrading enzyme. The latter may be important for initiating earlier metamorphosis in the pelagic larval stage of the flatfish studied.

\section{EPIGENETIC MECHANISMS INFLUENCED BY EMBRYO TEMPERATURE}

Phenotypic plasticity caused by temperature during embryonic development is not well studied, but it appears reasonable to assume that at least some of the variation is caused by epigenetic effects (Waddington 1942, 1953, Jonsson \& Jonsson 2014, Labbé et al. 2017). These can be DNA methylation and histone modifications that regulate gene expression at the level of chromatin structure and DNA, and microRNAs (miRNAs), i.e. small non-coding RNAs that constitute a post-transcriptional mechanism regulating abundance and translation of mRNAs (Bollati \& Baccarelli 2010, Best et al. 2018). Most epigenetic changes are confined to an individual organism's life-time. It is possible that epigenetic characters can be inherited (Chandler 2007), although this has been questioned by several authors, especially for higher vertebrates (e.g. Iqbal et al. 2015, Nadeau 2015, Szabó 2015, Horsthemke 2018). These effects are the emergent properties of the genome and the response to its environment (Holliday \& Grigg 1993, Kutschera \& Niklas 2004). Below, we give examples of how DNA methylation, histone modifications and miRNAs may interact with temperature during development in regulating phenotypic characters. 


\subsection{DNA methylation}

DNA methylation is the best studied and understood epigenetic mechanism (Metzger \& Schulte 2016). It inhibits genetic transcription and is stable at the time scale of an individual's lifespan. Changes in DNA methylation affect many developmental processes and occur in certain regions of the genome. Methylation typically refers to the addition of a methyl group to position 5 of cytosine bases when cytosine occurs adjacent to a guanine nucleotide (McGowan \& Martin 1997). However, it is becoming increasingly evident that significant methylation may also occur in non-cytosine-guanine contexts, at least in pluripotent cell types and oocytes (Ramsahoye et al. 2000, Tomizawa et al. 2011). Even modest increases in temperature can change the global methylation level of fish larvae. Anastasiadi et al. (2017) showed that a $2^{\circ} \mathrm{C}$ increase in temperature significantly changed the DNA methylation for larval Dicentrarchus labrax and simultaneously the expression of ecologically relevant genes related to stress responses as well as muscle and organ formation. Gene expression was more affected by temperature at the larval than the juvenile stage.

High levels of DNA methylation are associated with silencing of gene expression, and demethylation is linked to active gene transcription (Bird 2002). Temperature influences the intensity of the DNA methylation, and it occurs more abundantly in polar than in tropical and temperate marine species (Kakutani 2002, Varriale \& Bernardi 2006). The latter authors also reported that the Antarctic icefishes (Channichthyidae) had the highest methylation level that they found. These results confirm the existence of an inverse relationship between DNA methylation and body temperature. However, little is known about its functioning in fishes (Simonet et al. 2013).

Morán \& Pérez-Figueroa (2011) hypothesized that an environmentally induced methylation pattern of the genome, which alters its transcriptional properties, can cause maturation of young male Salmo salar (parr), hence being the basis for male size dimorphism of this species. Furthermore, in Gadus morhua, an increase of $4^{\circ} \mathrm{C}$ during egg incubation resulted in changes in the expression of genes involved in 1-carbon metabolism (transfer of 1 carbon group) and DNA methylation pathways (Skjærven et al. 2014). Furthermore, Baerwald et al. (2016) reported that DNA methylation was associated with smolting and migration in rainbow trout Oncorhynchus mykiss. Like $S$. trutta, this species exhibits populations consisting of both anadromous and nonana- dromous phenotypes (i.e. partial anadromy), and the similar genetics but different ecology of these 2 salmonid forms have long been a puzzle for biologists (Hindar et al. 1991, Docker \& Heath 2003, Giger et al. 2006). Although the ability to smolt appears genetically determined (Jonsson 1982, Metcalfe 1998), the onset of smolting can be fine-tuned by epigenetic modifications (Baerwald et al. 2016).

Burgerhout et al. (2017) studied body growth of $S$. salar developed from embryos incubated at $4^{\circ}$ and $8^{\circ} \mathrm{C}$ until the embryonic 'eyed-stage' followed by rearing at the production temperature of $8^{\circ} \mathrm{C}$. The warm-incubated fish were about twice as heavy as the coldincubated fish at smolting and transfer to seawater. Burgerhout et al. (2017) showed that larval myogenin expression was approximately 4-6-fold higher in the fastest-growing group treated with heated water than in the other groups. The fast growth was associated with relative low DNA methylation levels. Thus, DNA methylation appears to play a major role in phenotypic plasticity in structural muscle growth.

Metzger \& Schulte (2018) investigated phenotypic plasticity responses at different timescales of Gasterosteus aculeatus and underlying molecular processes. They found that gene expression changed in response to temperature during early development, and that this could be observed in the muscle transcriptome of adults.

DNA methylation is involved in sex transfer. Using half-smooth tongue sole Cynoglossus semilaevis, Shao et al. (2014) analysed the gonadal DNA methylomes and revealed that genes in the sex determination pathways are the major targets of substantial methylation modification during sexual reversal. Similarly, in Oreochromis niloticus, an increase in DNA methylation was observed with a water temperature increase of $8^{\circ} \mathrm{C}$ (Sun et al. 2016). Furthermore, males and hermaphrodites of Kryptolebias marmoratus were differently methylated at various genes, indicating that DNA methylation interacted with temperature during early development regulating the mating system with alternation between selfing and outcrossing.

Han et al. (2016) reported that the DNA methylation level of the genome increased after short-term exposure ( $5 \mathrm{~d}$ ) and decreased after long-term exposure (30 d) in cold water $\left(18^{\circ} \mathrm{C}\right)$ relative to similar exposures in warm water $\left(28^{\circ} \mathrm{C}\right)$. In all, $21 \%$ of DNA methylation peaks were differentially affected by cold relative to warm treatments of Danio rerio. Methylation of genes involved in multiple cold responsive biological processes were significantly affected, such as the antioxidant system, programmed cell death (apoptosis), 
chromatin modification and immune system development. These processes are responsive to cold stress through regulation of DNA methylation, possibly in concert with histone modifications (Han et al. 2016).

\subsection{Histone modifications}

Histone modifications include remodeling of the complex of DNA that is wrapped around 8 histone proteins. Together, they make up the chromatin (Pittman et al. 2013). Changing the wrap changes the gene expression (Bannister \& Kouzarides 2011). Modification of histone proteins includes altering the shape of the histone proteins, removing or adding methyl groups to the DNA. Other such changes are for instance phosphorylation and acetylation. Histone modifications act in biological processes such as transcriptional activation/inactivation, chromosome packaging and DNA damage/repair. Histone methylation and acetylation are parallel mechanisms. Methylation inhibits gene expression, whereas acetylation is associated with gene activation. Both are important in regulating the structure and function of chromatin.

In the case of environmental sex determination in D. labrax, temperature-dependent DNA methylation and histone modification patterns of the aromatase gene (cyp19a1) in embryonic gonads influence sex determination (Navarro-Martín et al. 2011); this was later validated for $O$. niloticus, another species exhibiting temperature-dependent sex determination (Wang et al. 2017). Furthermore, histone methylation and deacetylation appear involved in sex differentiation in the ricefield eel Monopterus albus (Zhang et al. 2013, Tachibana 2016). The latter authors suggested that histone modification, in addition to DNA methylation, may drive natural sex change and gonadal differentiation in vertebrates.

In Solea senegalensis, Carballo et al. (2018) demonstrated that egg incubation temperature initiated the metamorphosis and growth performance of this fish. There was a change in the expression of the DNA methyltransferases as well as histone modifications at hatching. In this species, incubation temperature modulates embryogenesis and later development and growth through endocrinological changes.

\section{3. miRNAs}

miRNAs are small non-coding RNA molecules in the cells that function at the post-transcriptional level in RNA silencing and regulation of gene expression.
miRNAs have important biological functions and are evolutionarily conserved. miRNAs are substantial contributors to regulatory networks of development and adaptive plasticity (Jaenisch \& Bird 2003, Campos et al. 2014). Experimentally, this was exemplified by Campos et al. (2013), who incubated $S$. senegalensis embryos at $15^{\circ}$ or $21^{\circ} \mathrm{C}$ until hatching, and then reared the fish at a common temperature of $21^{\circ} \mathrm{C}$. The higher incubation temperature was associated with expression of some miRNAs positively related to growth during segmentation and at hatching. The expression of the miRNAs was involved in lipid metabolism and energy production that differed between the temperatures. Furthermore, Bizuayehu et al. (2015) reported that temperature shifts during early ontogeny (embryonic and larval development) affected the miRNA repertoire of G. morhua with longterm consequences in the miRNA profile. Long-term effects of embryonic incubation temperature were observed regarding expression of some miRNAs in juvenile pituitary glands, gonads and liver. Bizuayehu et al. (2015) concluded that increased sea temperature seemed to affect the life history of Gadus morhua. Thus, miRNAs may play a role in temperatureinduced phenotypic plasticity of growth and lifehistory traits of at least some fishes.

\section{ADAPTIVE ADVANTAGE}

Environmentally induced epigenetic changes contribute to phenotypic plasticity (Massicotte et al. 2011) and increase the adaptive potential in changing environments. In the reported cases (e.g. Campos et al. 2013, Jonsson et al. 2014, Bizuayehu et al. 2015), temperature during early ontogeny drives phenotypic plasticity and allows organisms to cope better with conditions that they are expected to encounter later in life. Salmo salar developed from eggs incubated in warmer water feed more and therefore grow faster at the optimal temperature and produce larger eggs and more milt than those incubated from eggs reared in colder water (Finstad \& Jonsson 2012, Burgerhout et al. 2017). Biological production is higher under warmer conditions (if not constrained by other factors such as hypoxia), and higher food consumption that allows for more growth can be an advantage. More growth and having a heavier body for a given length allows the fish to produce larger gonads and eggs, which appear advantageous under warm conditions. Eggs richer in energy are optimal in warmer environments because conversion efficiency decreases with increasing temper- 
ature (Fleming \& Gross 1990). Furthermore, larger eggs cope better with hypoxia, which more frequently occurs in warmer water (Einum et al. 2002). A later return from the feeding area may be an adaptation to later spawning in a warmer climate. Thus, the reaction to a high egg incubation temperature with effects on later appearing fitness-related traits, and in some cases across generations, seems to be an example of adaptive phenotypic plasticity.

In a wider context, epigenetic effects may increase the potential for spreading of the species as discussed by Eirin-Lopez \& Putnam (2019). In the case of $S$. salar, strays spawning in foreign rivers may, through epigenetic mechanisms, rapidly become adapted to the thermal conditions of their new habitat and thereby improve their reproductive success in the new environment. This mechanism may be helpful in expanding their distribution limits.

\section{POLYPHENISM AND SPECIATION}

Salmonids often exhibit polyphenic forms, perhaps best known from Arctic charr Salvelinus alpinus (Hindar \& Jonsson 1982, Jonsson \& Jonsson 2001), European whitefish Coregonus lavaretus (Østbye et al. 2005, Steinbacher et al. 2017) and Salmo trutta (Ferguson \& Taggart 1991, Jonsson \& Jonsson 2011). Sympatric phenotypes often occur in pairs exhibiting a large and a dwarf form, but sometimes more than 2 sympatric forms occur. For instance, Snorrason et al. (1994) described 4 adult phenotypes of $S$. alpinus in Lake Thingvallavatn, Iceland.

Differences in egg incubation temperature may contribute to this morph differentiation. Steinbacher et al. (2017) revealed this by incubating embryos of a large and a dwarf form of C. lavaretus at $2^{\circ}$ and $6^{\circ} \mathrm{C}$, i.e. the typical temperature during embryogenesis of large and dwarf C. lavaretus in nature, respectively. Both groups of offspring were subjected to similar thermal treatments after hatching. The offspring differentiated in body size and muscle growth depending on the egg incubation temperature; fish incubated at $2^{\circ} \mathrm{C}$ grew larger than those at $6^{\circ} \mathrm{C}$, regardless of whether their parents were large of dwarf C. lavaretus. Results also demonstrated that the hypertrophic and hyperplastic muscle growth modes were similarly affected by thermal histories. Immunolabelling provided evidence that the cellular mechanisms leading to increased growth after cold incubation in both ecotypes were increased proliferation and reduced differentiation rates of muscle precursor cells, most probably associated with epigenetic differences.
Conspecific forms of other salmonids are also known to spawn at different times and/or locations during embryogenesis (Hindar \& Jonsson 1982, Ferguson \& Taggart 1991), and a similar mechanism may initiate the phenotypic difference as described for $C$. lavaretus. How early environment can induce epigenetic reprogramming was revealed in experiments with coho salmon Oncorhynchus kisutch. Hatchery and wild salmonids differ in morphology, ecology and fitness when co-occurring in nature (Jonsson \& Jonsson 2006). In relation to this, Le Luyer et al. (2017) compared patterns of methylation and DNA variation in hatchery-reared and naturally occurring $O$. kisutch in 2 geographically distant rivers. The rearing environment explained a large part of the ecological and epigenetic variation. The authors found evidence of epigenetic modifications induced by hatchery rearing of the fish from both rivers. Differentially methylated regions exhibited enrichment for biological functions that may influence migratory and reproductive capacities of the fish.

Over the long term, epigenetic divergence may be a first step in speciation of North American darter species (Percidae) (Smith et al. 2016). These authors hypothesized that heritable epigenetic marks that increase fitness should increase in frequency in a population, and that these changes may result in novel morphology, behaviour, physiology and ultimately reproductive isolation. Therefore, epigenetic variation might provide the first substrate for selection during evolutionary divergence. Smith et al. (2016) demonstrated that epigenetic divergence is a predictor of the strength of behavioural reproductive isolation and suggested that changes in the methylome could influence the evolution of reproductive isolation between darter species. They claimed that their findings suggested a role for epigenetics not only in the initiation of divergence, but also in the maintenance of species boundaries over greater evolutionary timescales in this percid group.

\section{WIDER SIGNIFICANCE}

In a warmer climate, fish will at least partly adapt through phenotypic plasticity. This is a much faster reaction to temperature changes than that caused by evolution driven by natural selection. The latter process is assumed to be too slow to save many species under the present climate change. For instance, winter skate Leucoraja ocellata from the southern Gulf of St. Lawrence have adapted to $10^{\circ} \mathrm{C}$ warmer water with less oxygen content by dramatically decreasing 
their body size (Lighten et al. 2016). They have achieved this by epigenetically modifying the gene expression allowing for the physiological change. The DNA structure is not modified relative to a population living in colder habitats, but the methylation pattern and gene expression are significantly altered. Whereas evolution occurs very slowly over several generations, epigenetic changes take place within 1 generation and can carry populations through severe habitat and climate changes.

Salmo salar changes ecological characters depending on the water temperature during embryogenesis. Temperatures at northern latitudes are expected to increase most during winter (IPCC 2013), when salmonid eggs typically incubate in nature. For instance, a higher egg incubation temperature allows juvenile $S$. salar to grow faster, smolt younger and produce larger offspring, and delay time of the return migration from the ocean, all of which are adaptations advantageous in a warmer climate (Jonsson \& Jonsson 2018). We assume that other anadromous populations will exhibit a similar thermal response to temperature during embryogenesis. For fish spawning in foreign locations, this phenotypic flexibility can adapt offspring quickly to new thermal environments.

To speed up the developmental rate of hatchery salmon, managers often heat the water during embryogenesis to approximately $8^{\circ} \mathrm{C}$, viewed to be optimal for this species (Jonsson \& Jonsson 2011). When these salmon are released to enhance or conserve populations, the higher incubation temperature will influence the ecology of the fish. Therefore, sea ranched $S$. salar probably return later in summer to the river from where they outmigrated than wild individuals from the same population do (Jonsson et al. 1990, Jonsson \& Jonsson 2018).

Understanding the effects of early influences on the ecology of species is a growing, but under-researched field. We believe that many intraspecific population differences, earlier believed to be examples of adaptive differences, are examples of phenotypic plasticity resulting from epigenetic modification, as the research summarized above indicates. However, such effects are difficult to uncover because phenotypic traits caused by the early environment are cryptic and may even be inherited across generations.

\section{FUTURE RESEARCH}

Research on how the early environment influences genotypes and forms phenotypes, and mechanisms involved, is still in its youth. There is little knowledge about the processes leading to variation in appearance, physiology, life history and behaviour, i.e. phenotypic variation. Early temperature is one of many external variables that affects phenotypic development. Oxygen level, toxic contaminants, nutrition, social environment with competition, parasites and predation also influence genotypic expressions. Future research should focus on how signals from environmental stressors trigger molecular biological changes of brain cells, and how this is transmitted to phenotypic characters and ecological decisions.

In this review, we focussed on 1 factor, namely the effects of early temperature. Future global temperature is expected to increase (IPCC 2013). In this context, new research should focus on how this change will affect populations and investigate to what degree populations buffer changes through phenotypic plasticity. For instance, there is little knowledge about how early environment affects migration versus residency of partly migratory species, and how early climate affects the timing of migrations before and after spawning. The mechanisms allowing this plasticity are largely unknown, although epigenetic changes caused by increased embryonic temperature appear involved (Jonsson \& Jonsson 2014, 2018, Baerwald et al. 2016). Although the environment appears to play a key role in the ecology of species, these and similar relationships are still understudied.

Acknowledgements. This review was supported by the Norwegian Research Council, project 268005 of Klimaforsk.

\section{LITERATURE CITED}

Anastasiadi D, Diaz N, Pifferer F (2017) Small ocean temperature increases elicit stage-dependent changes in DNA methylation and gene expression in a fish, the European sea bass. Sci Rep 7:12401

*Baerwald MR, Meek MH, Stephens MR, Nagarajan RP and others (2016) Migration-related phenotypic divergence is associated with epigenetic modifications in rainbow trout. Mol Ecol 25:1785-1800

Bannister AJ, Kouzarides T (2011) Regulation of chromatin by histone modifications. Cell Res 21:381-395

* Baroiller JF, D'Cotta H (2001) Environment and sex determination in farmed fish. Comp Biochem Physiol C Toxicol Pharmacol 130:399-409

* Bertin A, Calandreau L, Meurisse M, Georgelin M and others (2018) Incubation temperature affects the expression of young precocial birds' fear-related behaviours and neuroendocrine correlates. Sci Rep 8:1857

Best C, Ikert H, Kostyniuk DJ, Craig PM, Navarro-Martin L, Marandel L, Mennigen JA (2018) Epigenetics in teleost fish: from molecular mechanisms to physiological phenotypes. Comp Biochem Phys B Biochem Mol Biol 224: $210-244$ 
Bird A (2002) DNA methylation patterns and epigenetic memory. Genes Dev 16:6-21

Bizuayehu TT, Johansen SD, Puvanendran V, Toften $\mathrm{H}$, Babiak I (2015) Temperature during early development has long term effects on microRNA expression in Atlantic cod. BMC Genomics 16:305

Bollati V, Baccarelli A (2010) Environmental epigenetics. Heredity 105:105-112

* Braun DC, Patterson DA, Reynolds JD (2013) Maternal and environmental influences on egg size and juvenile lifehistory traits in Pacific salmon. Ecol Evol 3:1727-1740

Burgerhout E, Mommens M, Johnsen H, Aunsmo A, Santi N, Andersen $\varnothing$ (2017) Genetic background and embryonic temperature affect DNA methylation and expression of myogenin and muscle development in Atlantic salmon (Salmo salar). PLOS ONE 12:e0179918

Campos C, Valente LMP, Conceicao LEC, Engrola S, Sousa V, Rocha E, Fernandes JMO (2013) Incubation temperature induces changes in muscle cellularity and gene expression in Senegalese sole (Solea senegalensis). Gene 516:209-217

* Campos C, Valente LMP, Conceicao LEC, Engrola S, Fernandes JMO (2014) Molecular regulation of muscle development and growth in Senegalese sole larvae exposed to temperature fluctuations. Aquaculture 432: 418-425

* Carballo C, Firmino J, Anjos L, Santos S, Power DM, Manchad M (2018) Short- and long-term effects on growth and expression patterns in response to incubation temperatures in Senegal sole. Aquaculture 495:222-231

Chandler VL (2007) Paramutation: from maize to mice. Cell 128:641-645

Colchen T, Teletchea F, Fontaine P, Pasquet A (2017) Temperature modifies activity, inter-individual relationships and group structure in a fish. Curr Zool 63:175-183

Cook CJ, Wilson CC, Burness, G (2018) Impacts of environmental matching on the routine metabolic rate and mass of native and mixed-ancestry brook trout (Salvelinus fontinalis) fry. Conserv Physiol 6:coy023

* Docker MF, Heath DD (2003) Genetic comparison between sympatric anadromous steelhead and freshwater resident rainbow trout in British Columbia, Canada. Conserv Genet 4:227-231

Dubinska-Magiera M, Daczewska M, Lewicka A, MigockaPatrzałek M, Niedbalska-Tarnowska J, Jagla K (2016) Zebrafish: a model for the study of toxicants affecting muscle development and function. Int J Mol Sci 17:1941

Einum S, Hendry AP, Fleming IA (2002) Egg-size evolution in aquatic environments. Does oxygen availability constrain size? Proc R Soc B 269:2325-2330

Eirin-Lopez JM, Putnam HM (2019) Marine environmental epigenetics. Annu Rev Mar Sci 11:335-368

Ellison A, Rodríguez López CM, Morán P, Breen J and others (2015) Epigenetic regulation of sex ratios may explain natural variation in self-fertilization rates. Proc R Soc B 282:20151900

Ferguson A, Taggart JB (1991) Genetic differentiation among the sympatric brown trout (Salmo trutta) populations of Lough Melvin, Ireland. Biol J Linn Soc 43:221-237

* Finstad AG, Jonsson B (2012) Effect of incubation temperature on growth performance in Atlantic salmon. Mar Ecol Prog Ser 454:75-82

Fleming IA, Gross MR (1990) Latitudinal clines: a trade-off between egg number and size in Pacific salmon. Ecology 71:1-11
Forster J, Hirst AG, Atkinson D (2012) Warming-induced reductions in body size are greater in aquatic than terrestrial species. Proc Natl Acad Sci USA 109: 19310-19314

* Giger T, Excoffier L, Day PJR, Champigneulle A, Hansen MM, Powell R, Largiader CR (2006) Life history shapes gene expression in salmonids. Curr Biol 16:R281-R282

Gudsnuk KM, Champagne FA (2011) Epigenetic effects of early developmental experiences. Clin Perinatol 38: 703-717

Han B, Li W, Chen Z, Xu Q and others (2016) Variation in DNA methylome of zebrafish cells under cold pressure. PLOS ONE 11:e0160358

* Hansen LP, Jonsson N, Jonsson B (1993) Oceanic migration of homing Atlantic salmon. Anim Behav 45:927-941

*Hayashi Y, Kobira H, Yamaguchi T, Shiraishi E and others (2010) High temperature causes masculinization of genetically female medaka by elevation of cortisol. Mol Reprod Dev 77:679-686

* Hindar K, Jonsson B (1982) Habitat and food segregation of dwarf and normal Arctic charr (Salvelinus alpinus) from Vangsvatnet Lake, western Norway. Can J Fish Aquat Sci 39:1030-1045

* Hindar K, Jonsson B, Ryman N, Ståhl G (1991) Genetic relationships among landlocked, resident, and anadromous brown trout, Salmo trutta L. Heredity 66:83-91

*Ho DH, Berggren WW (2012) Parental hypoxic exposure confers offspring hypoxia resistance in zebrafish (Danio rerio). J Exp Biol 215:4208-4216

*Holliday R, Grigg GV (1993) DNA methylation and mutation. Mutat Res 285:61-67

* Horsthemke B (2018) A critical view on transgenerational epigenetic inheritance in humans. Nat Commun 9:2973

IPCC (Intergovernmental Panel on Climate Change) (2013) Climate change 2013: the physical science basis. Contribution of Working Group I to the Fifth Assessment Report of the Intergovernmental Panel on Climate Change. www.ipcc.ch/report/ar5/wg1/\#.UnisDLUiSGI

* Iqbal K, Tran DA, Li AX, Warden C and others (2015) Deleterious effects of endocrine disruptors are corrected in the mammalian germline by epigenome reprogramming. Genome Biol 16:59

Jaenisch R, Bird A (2003) Epigenetic regulation of gene expression: how the genome integrates intrinsic and environmental signals. Nat Genet 33:245-254

Johnston IA, Lee HT, Macqueen DJ, Parantheman K and others (2009) Embryonic temperature affects muscle fiber recruitment in adult zebrafish: genome-wide changes in gene and microRNA expression associated with the transition from hyperplastic to hypertrophic growth phenotypes. J Exp Biol 212:1781-1793

Jonsson B (1982) Diadromous and resident trout Salmo trutta: Is their difference due to genetics? Oikos 38:297-300

* Jonsson B, Jonsson N (2001) Polymorphism and speciation in Arctic charr. J Fish Biol 58:605-638

Jonsson B, Jonsson N (2006) Cultured salmon in nature: a review of their ecology and interactions with wild fish. ICES J Mar Sci 63:1162-1181

Jonsson B, Jonsson N (2011) Ecology of Atlantic salmon and brown trout: habitat as a template for life histories. Fish Fish Ser 33. Springer, Dordrecht

Jonsson B, Jonsson N (2014) Early environment influences later performance in fishes. J Fish Biol 85:151-188

* Jonsson B, Jonsson N (2016) Trans-generational maternal effect: temperature influences egg size of the offspring in 
Atlantic salmon Salmo salar. J Fish Biol 89:1482-1487

Jonsson B, Jonsson N (2018) Egg incubation temperature affects the timing of the Atlantic salmon Salmo salar homing migration. J Fish Biol 93:1016-1020

Jonsson B, Jonsson N, Hansen LP (1990) Does juvenile experience affect migration and spawning of adult Atlantic salmon? Behav Ecol Sociobiol 26:225-230

Jonsson B, Jonsson N, Finstad AG (2013) Effects of temperature and food quality on age at maturity of ectotherms: an experimental test of Atlantic salmon. J Anim Ecol 82: 201-210

Jonsson B, Jonsson N, Finstad AG (2014) Linking embryonic temperature with adult reproductive investment in Atlantic salmon Salmo salar. Mar Ecol Prog Ser 515: 217-226

Jonsson B, Jonsson M, Jonsson N (2016) Optimal size at seaward migration in an anadromous salmonid. Mar Ecol Prog Ser 559:193-200

Jonsson N, Jonsson B, Hansen LP (2003) Marine survival and growth of sea ranched and wild Atlantic salmon. J Appl Ecol 40:900-911

Jonsson N, Jonsson B, Hansen LP (2005) Does climate during embryonic development influence parr growth and age of seaward migration in Atlantic salmon (Salmo salar) smolts? Can J Fish Aquat Sci 62:2502-2508

Kakutani T (2002) Epi-alleles in plants: inheritance of epigenetic information over generations. Plant Cell Physiol 43: 1106-1111

Kitano J, Peichel CL (2012) Turnover of sex chromosomes and speciation in fishes. Environ Biol Fishes 94:549-558

Kutschera U, Niklas KJ (2004) The modern theory of biological evolution: an expanded synthesis. Naturwissenschaften 91:255-276

Kabbé C, Robles V, Gerraez MP (2017) Epigenetics in fish gametes and early embryo. Aquaculture 472:93-106

Le Luyer J, Laporte M, Beacham TD, Kaukinen KH and others (2017) Parallel epigenetic modifications induced by hatchery rearing in a Pacific salmon. Proc Natl Acad Sci USA 114:12964-12969

* Lighten J, Incarnato D, Ward BJ, van Oosterhout C, Bradbury I, Hanson M, Bentzen P (2016) Adaptive phenotypic response to climate enabled by epigenetics in a K-strategy species, the fish Leucoraja ocellata (Rajidae). R Soc Open Sci 3:160299

Lindström J (1999) Early development and fitness in birds and mammals. Trends Ecol Evol 14:343-348

* Liu J, Dias K, Plagnes-Juan E, Veron V, Panserat S, Marandel L (2017) Long-term programming effect of embryonic hypoxia exposure and high-carbohydrate diet at first feeding on glucose metabolism in juvenile rainbow trout. J Exp Biol 220:3686-3694

Malekpour M (2007) Effects of attachment on early and later development. Br J Dev Disabil 53:81-95

Massicotte R, Whitelaw E, Angers B (2011) DNA methylation: a source of random variation in natural populations. Epigenetics 6:421-427

McGowan RA, Martin CC (1997) DNA methylation and genome imprinting in zebrafish, Danio rerio: some evolutionary ramifications. Biochem Cell Biol 75:499-506

* McLennan D, Armstrong JD, Stewart DC, Mckelvey S, Boner W, Monaghan P, Metcalfe NB (2016) Interactions between parental traits, environmental harshness and growth rate in determining telomere length in wild juvenile salmon. Mol Ecol 25:5425-5438

Metcalfe NB (1998) The interaction between behavior and physiology in determining life history patterns in Atlantic salmon (Salmo salar). Can J Fish Aquat Sci 55: 93-103

* Metzger DCH, Schulte PM (2016) Epigenomics in marine fishes. Mar Genomics 30:43-54

Metzger DCH, Schulte PM (2018) Similarities in temperature-dependent gene expression plasticity across timescales in threespine stickleback (Gasterosteus aculeatus). Mol Ecol 27:2381-2396

*Montalvo AJ, Faulk CK, Holt GJ (2012a) Sex determination in southern flounder, Paralichthys lethostigma, from the Texas Gulf Coast. J Exp Mar Biol Ecol 432-433:186-190

* Montalvo C, Villar AV, Merino D, García R and others (2012b) Androgens contribute to sex differences in myocardial remodelling under pressure overload by a mechanism involving TGF- $\beta$. PLOS ONE 7:e35635

* Morán P, Pérez-Figueroa A (2011) Methylation changes associated with early maturation stages in the Atlantic salmon. BMC Genet 12:86

Mousseau TA, Fox CW (1998) The adaptive significance of maternal effects. Trends Ecol Evol 13:403-407

Nadeau JH (2015) The nature of evidence for and against epigenetic inheritance. Genome Biol 16:137

Navara KJ (2018) Choosing sexes: mechanisms and adaptive patterns of sex allocation in vertebrates. Springer, Cham

*Navarro-Martín L, Vinas J, Ribas L, Diaz N, Gutierrez A, Di Croce L, Piferrer F (2011) DNA methylation of the gonadal aromatase (cyp19a) promotor is involved in temperature-dependent sex ratio shifts in the European sea bass. PLOS Genet 7:e1002447

* Nivelle R, Gennotte V, Kalala EJK, Ngoc NB, Muller M, Mélard C, Rougeot C (2019) Temperature preference of Nile tilapia (Oreochromis niloticus) juveniles induces spontaneous sex reversal. PLOS ONE 14(2): e0212504

O'Connell FM, Ash EGM (1993) Smolt size in relation to age at first maturity of Atlantic salmon (Salmo salar): the role of lacustrine habitat. J Fish Biol 42:551-559

* Omoto N, Koya Y, Chin B, Yamashita Y, Nakagawa M, Noda $\mathrm{T}$ (2010) Gonadal sex differentiation and effect of rearing temperature on sex ratio in black rockfish (Sebastes schlegeli). Ichthyol Res 57:133-138

Ospina-Álvarez N, Piferrer F (2008) Temperature-dependent sex determination in fish revisited: prevalence, a single sex ratio response pattern, and possible effects of climate change. PLOS ONE 3:e2837

Østbye K, Bernatchez L, Næsje TF, Himberg KJ, Hindar K (2005) Evolutionary history of the European whitefish Coregonus lavaretus (L.) species complex as inferred from mtDNA phylogeography and gill-raker numbers. Mol Ecol 14:4371-4387

Patiño R, Davis KB, Schoore JE, Uguz C and others (1996) Sex differentiation of channel catfish gonads: normal development and effects of temperature. J Exp Zool 276: 209-218

* Peters DPC, Yao J, Sala OE, Anderson JP (2012) Directional climate change and potential reversal of desertification in arid and semiarid ecosystems. Glob Change Biol 18: 151-163

* Pigliucci M, Murren CJ, Schlichting CD (2006) Phenotypic plasticity and evolution by genetic assimilation. J Exp Biol 209:2362-2367

* Pittman K, Yúfera M, Pavlidis M, Geffen AJ and others (2013) Fantastically plastic: fish larvae equipped for a new world. Rev Aquacult 5(Suppl 1):S224-S267 
Quinn TP, McGinnity P, Reid TE (2016) The paradox of 'premature migration' by adult anadromous salmonid fishes: patterns and hypotheses. Can J Fish Aquat Sci 73: 1015-1030

Ramsahoye BH, Biniszkiewicz D, Lyko F, Clark V, Bird AP, Jaenisch R (2000) Non-CpG methylation is prevalent in embryonic stem cells and may be mediated by DNA methyltransferase 3a. Proc Natl Acad Sci USA 97: 5237-5242

Salinas S, Munch SB (2012) Thermal legacies: transgenerational effects of temperature on growth in a vertebrate. Ecol Lett 15:159-163

Schnurr ME, Yin Y, Scott GR (2014) Temperature during embryonic development has persistent effects on metabolic enzymes in the muscle of zebrafish. J Exp Biol 217: $1370-1380$

Schultz ET (2008) A sex difference in seasonal timing of birth in a live bearing fish. Copeia 2008:673-679

Scott GR, Johnston IA (2012) Temperature during embryonic development has persistent effects on thermal acclimation capacity of zebrafish. Proc Natl Acad Sci USA 109:14247-14252

Shama LNS, Wegner KM (2014) Grandparental effects in marine sticklebacks: transgenerational plasticity across multiple generations. J Evol Biol 27:2297-2307

Shao C, Li Q, Chen S, Zhang P and others (2014) Epigenetic modification and inheritance in sexual reversal of fish. Genome Res 24:604-615

Shine R, Olsson M (2003) When to be born? Prolonged pregnancy or incubation enhances locomotor performance in neonatal lizards (Scincidae). J Evol Biol 16:823-832

Simonet NG, Reyes M, Nardocci G, Molina A, Alvarez M (2013) Epigenetic regulation of the ribosomal cistron seasonally modulates enrichment of H2A.Z and H2A.Zub in response to different environmental inputs in carp (Cyprinus carpio). Epigenet Chromatin 6:22

Skjærven KH, Hamre K, Penglase S, Finn RN, Olsvik PA (2014) Thermal stress alters expression of genes involved in one carbon and DNA methylation pathways in Atlantic cod embryos. Comp Biochem Physiol A Mol Integr Physiol 173:17-27

Smith TA, Martin MD, Nguyen M, Mendelson TC (2016) Epigenetic divergence as a potential first step in darter speciation. Mol Ecol 25:1883-1894

Snorrason SS, Skulason S, Jonsson B, Malmquist H, Jonasson PM, Sandlund OT, Lindem T (1994) Trophic specialization in Arctic charr Salvelinus alpinus (Pisces: Salmonidae): morphological divergence and ontogenetic shifts. Biol J Linn Soc 52:1-18

Steinbacher P, Wanzenböck J, Brandauer M, Holper R and others (2017) Thermal experience during embryogenesis contributes to the induction of dwarfism in whitefish Coregonus lavaretus. PLOS ONE 12:e0185384

Stickland NC, White RN, Mescall PE, Crook AR, Thorpe JE

Editorial responsibility: Victor Benno Meyer-Rochow, Oulu, Finland
(1988) The effect of temperature on myogenesis in embryonic development of the Atlantic salmon (Salmo salar L.). Anat Embryol 178:253-257

N Sun LX, Wang YY, Zhao Y, Wang H, Li N, Ji XS (2016) Global DNA methylation changes in Nile tilapia gonads during high temperature-induced masculinization. PLOS ONE 11:e0158483

Szabó PE (2015) Response to: the nature of evidence for and against epigenetic inheritance. Genome Biol 16:138

Tachibana M (2016) Epigenetics of sex determination in mammals. Reprod Med Biol 15:59-67

* Tåning AV (1952) Experimental study of meristic characters in fishes. Biol Rev Camb Philos Soc 27:169-193

Tattam IA, Ruzycki JR, McCormick JL, Carmichael RW (2015) Length and condition of wild Chinook salmon smolts influence age at maturity. Trans Am Fish Soc 144: $1237-1248$

Taylor DS (2012) Twenty-four years in the mud: What have we learned about the natural history and ecology of the mangrove rivulus, Kryptolebias marmoratus? Integr Comp Biol 52:724-736

* Tomizawa S, Kobayashi H, Watanabe T, Andrews S, Hata K, Kelsey G, Sasaki H (2011) Dynamic stage-specific changes in imprinted differentially methylated regions during early mammalian development and prevalence of non-CpG methylation in oocytes. Development 138: 811-820

Turner BM (2009) Epigenetic responses to environmental change and their evolutionary implications. Philos Trans R Soc B 364:3403-3418

*Valenzuela N, Adams DC, Janzen FJ (2003) Pattern does not equal process: Exactly when is sex environmentally determined? Am Nat 161:676-683

* Varriale A, Bernardi G (2006) DNA methylation and body temperature in fishes. Gene 385:111-121

Vernerback C (2016) Effect of incubation temperature on Atlantic salmon metabolism as indicated by ventilation rate. MSc thesis, Karlstad University

*Waddington $\mathrm{CH}$ (1942) Canalization of development and the inheritance of acquired characters. Nature 150: 563-565

Waddington $\mathrm{CH}$ (1953) Genetic assimilation of an acquired character. Evolution 7:118-126

Wang SY, Lau K, Lai KP, Zhang JW and others (2016) Hypoxia causes transgenerational impairments in reproduction of fish. Nat Commun 7:12114

Wang YY, Sun LX, Zhu JJ, Zhao Y, Wang H, Liu HJ, Ji XS (2017) Epigenetic control of cyp19a1a expression is critical for high temperature induced Nile tilapia masculinization. J Therm Biol 69:76-84

Zhang Y, Zhang S, Liu Z, Zhang L, Zhang W (2013) Epigenetic modifications during sex change repress gonadotropin stimulation of Cyp19a1a in a teleost ricefield eel (Monopterus albus). Endocrinology 154:2881-2890

Submitted: November 30, 2018; Accepted: February 14, 2019 Proofs received from author(s): March 31, 2019 